\title{
The Influence of the Region after Ethnic Migration on Residential Buildings - Taking the Migration Activity of "Braving the Journey to Northeast" as an Example
}

\author{
Huiruo Xi \\ Faculty of Architecture and City Planning, Kunming University of Science and Technology, Kunming 650504, Yunnan, China \\ Email: 1459005660@qq.com
}

\begin{abstract}
There have been many ethnic migration activities in Chinese history. In the meantime, the architectural thinking of the tribes who traveled to the place of arrival has a process of transformation, and this process also reflects the influence of the region on the choice of architectural form. This article will examine the development process of residential buildings, and by comparing the similarities and differences of residential buildings in the place of departure and arrival of the migrating ethnic group, it will study the catalytic effect of the region on the evolution of the residential building form of the migrating ethnic group.
\end{abstract}

Keywords: ethnic migration, residential buildings, regionality

\section{Introduction}

\subsection{Related definitions}

\subsubsection{Ethnic migration}

In ethnology, ethnic group refers to a collection of ethnic groups that are geographically close, similar in language, have the same ancestry, and have the same culture. Migration refers to the migration activities of people in ethnic groups at a certain distance due to a series of reasons such as climate, reproduction, and changes in food. In the history of our country, there are two main reasons for the migration of ethnic groups: one is natural disasters, wars, and harsh government in the original place; the other is that the migration destination has better natural resources or social environment.

\subsubsection{Migrating buildings}

The so-called migratory architecture refers to a building that fully responds to the natural and humanistic conditions of the place of emigration after it has migrated to the place of emigration after the real development of the cultural origin and has the cultural characteristics of the place of emigration. Although the time of migration is at the same level of social development from the perspective of long-term historical stages, and the evolution of the building after migration is still a process of close integration with the surrounding environment, the migration of buildings is also affected by its source. , The prototype of the emigration place and the influence of the emigration place present an "unnatural" state, that is, "alien growth". The buildings built by the immigrants are the most typical migratory buildings. They migrate with the migration of the immigrant subjects, and they have similarities and differences with the changes of the geographical environment.

\subsubsection{Breakthrough}

The east gate of Shanhaiguan city defines the land of the Central Plains outside and inside Shanhaiguan. "Braving the Journey to Northeast" in this article refers to the historical period from the Tongzhi period of the Qing Dynasty to the Republic of China, when a large number of people in the Central Plains crossed Shanhaiguan, crossed the Bohai Sea, and settled in the Northeast.

\subsection{Research purpose}

Ethnic migration belongs to the research category of anthropology. Studying the changes of residential buildings with the change of location in the typical ethnic migration activity of "Braving the Journey to Northeast" will help to broaden the horizons of architecture and understand the specific architectural thinking in special periods and special events.

\section{Research content and methods}

This article will take the evolution of residential buildings in ethnic migration as the theme. Based on the study of regional architecture, starting from the relationship between the region and the building, the typical migration event of 
"Braving the Journey to Northeast" is selected as the research object. The characteristics of the residential buildings in the emigration area (Shandong area) and the emigration area (Northeast area) involved in "Braving the Journey to Northeast" are compared with the similarities and differences, so as to verify the influence of ethnic migration on the evolution of architecture.

\section{Regions and residential buildings}

Geography is the basis for the emergence and development of all human culture. Based on the knowledge of cultural geography, this article studies the relationship between human beings and their production and living activities and the geographical environment from the perspective of space.

\subsection{Geographical analysis}

The area affected by the "Braving the Journey to Northeast" incident is the entire three provinces in Northeast China, especially the south and the west, which are relatively close. Migration has also created a number of representative immigrant cities. In the wave of migration, the immigrant population in the destination area has increased exponentially, the social composition has been completely changed, and the strong dynamism of the immigrant culture has shaken the aborigines. The Qilu culture from its place of origin radiated to the outside world, changing the cities and towns.

\subsection{Northeast residence and Jiaodong residence}

\subsubsection{Natural environment}

In most parts of Northeast of China, the winter is long and the summer is short. Therefore, the focus of the construction of local residential buildings is to prevent the cold. The aborigines have used natural conditions for a long time to resist the severe cold climate. In the semi-burrow-style life of resisting the cold, they gradually summed up a complete system of cold protection and heating experience, inventing heating methods such as "the heated brick bed". Residential buildings are designed to match the heating method. It is a good way to get wood from the forest. In contrast, the Jiaodong area is surrounded by the sea on three sides, with a long coastline, many harbors, islands, and hills in the middle. All over, the north and south plains are open. Due to the intervention of the two major objects of mountain and ocean, Jiaodong residential houses are facing various grounding problems. The aborigines must also consider preventing the invasion of natural forces such as the ocean and monsoon while they are leaning against the mountains and rivers. Therefore, in addition to meeting the basic living conditions, the Jiaodong dwellings should also pay attention to moisture prevention during the construction process.

\subsubsection{Humanistic background.}

Among the aborigines in Northeast China, the Manchu lived for a long time, so they developed a high degree of civilization and always had close contact with the Han nationality. The region has both Korean, Mongolian and other ethnic minorities, showing a multi-ethnic cultural situation. The culture of ethnic minorities has an influence on the modeling and decoration of folk houses. On the other hand, the Jiaodong area presents the characteristics of Chinese culture based on the Dahe civilization, and is mainly enlightened by Confucianism, and the basic architectural concept is mainly "relocate again". Because it is located near the sea and is greatly influenced by marine civilization, convenient shipping and marine resources make local dwellings have better access to foreign technology, materials and craftsmen.

\subsubsection{Residential building materials and local conditions}

Northeast folk houses are often based on local materials in Changbai Mountains, Greater Khingan Mountains and other mountainous areas, often using logs stacked into walls to build wooden walls. They may use clay and reeds to stir to make "earthen bricks", which can be dried and fired to increase their strength to keep out the cold. The toughness of Reed grass is better, when the economic condition is poor, it can cover multi-layer instead of brick roof, and fill joints with mud to prevent heat loss. The materials of folk houses in Jiaodong come from various sources. For example, there are two main sources of stone: one is the stone derived from the mountains, and the other is the stone imported by sea from other regions. Bricks and tiles-especially burn them in cool colors such as black. The representative color of water is used to express the aboriginal people's admiration for the ocean. The covering material of the roof has appeared quite characteristic kelp grass, which contains colloid, iodized salt, particularly tough, can prevent sea erosion, moth, decay, strong wind resistance, and can be found everywhere along the coast, so it is a very good building material.

The monomer of the northeast residence often takes a heated brick bed as the basic living unit, which is regenerated into a plane, which is formed by creating an airtight wall. In addition, the houses in the whole settlement are located in the leeward to the sun, loosely relying on together to resist the cold wind. The most common architectural form of folk houses in Jiaodong is courtyard style, and quadrangles are preferred. The courtyard is arranged in the north-south direction along 
the street, and houses are built around the courtyard. The five main rooms sit from north to south, with wings in the east and west and inverted seats in the south. The second room to the east of the inverted seat opens the door, and the first room stores sundries. The courtyard is divided by walls, the front yard is small, the backyard is large and is used as a living space.

\subsection{Actual cases}

\subsubsection{Zhang's House in Shangzhi, Heilongjiang Province}

Zhang's House is a traditional well-dried house in the eastern forest area of Heilongjiang Province. It faces south and faces north and runs horizontally with other houses in the village. The plane is in the form of a rectangle. There is a threeroom main house and two warehouses in the courtyard. There are toilets at the back and courtyards in front of the house. The basic functions of agricultural life are arranged on the four sides, and the east gable has a high-rise penthouse on the ground floor.

The construction process of Zhang's house is very meticulous. The structure is constructed by nailing straw stalks on the fork hands, spreading Leymus chinensis on the top, clamping the grass with straw stalks, and tying them to prevent wind. The indoor ceiling is paved with small logs, plastered with mud to keep warm, there are no pillars in the house, and there is a complete small pavilion on the top that can store food, and the door is opened on the gable wall and there is a ladder for access.

\subsubsection{Mou's Manor, Qixia County, Shandong Province}

Mou's Manor is a typical courtyard house with a large building area and complete functions. There are three groups of six houses arranged in east and west. There is no wing room in the courtyard in front of the main hall. The courtyard is spacious and bright for worshiping ancestors and expressing etiquette in hospitality. The other courtyards are relatively independent and private, with a sense of intimacy in life. During the construction process, granite was used to sit on the abutment. In addition, many well-carved stone bricks were used for elegant decoration.

\subsubsection{Seaweed Houses in Lidao, Shandong Province}

The kelp thatched house is simple in shape. The most special feature is that the roof is laid alternately with one layer of wheat straw and one layer of seaweed. The eaves are neatly cut and sealed with plaster or tubing to prevent sea breeze, and the slope is steep to prevent rain and snow.

\subsection{Integration of residential buildings}

With the continuous deepening of Jiaodong immigrants to open up the customs, the two major folk architectures of northeast residential and Jiaodong residential meet and influence each other. Originally simple in form and without an inner courtyard, the northeastern houses gradually moved closer to it. Life outside the Shanhaiguan was gradually prosperous and stable. Everyone yearned for a higher quality of life and had more fruitful labor results. For a time, it emerged outside the Shanhaiguan. Many courtyard-style buildings, these buildings have the advantages of two kinds of civil architecture. The rich in towns choose courtyard houses as their residences. This pattern can provide a relatively secret courtyard space, and also separates the class status relationship between the master, the subordinates, and the long-time workers, and reflects the traditional hierarchical thinking and the theory of the five elements. The details such as the red windows, red doors, and painted fences also reflect the characteristics of folk customs after the integration of the folk system.

\section{Conclusion}

The residential form of a certain ethnic group mainly depends on the construction experience of its residents as a whole. These experiences are often the result of people's proactive or passive adaptation to nature through long-term construction practices. Construction experience is a relatively stable system in Chinese civilization. Under the condition that the external conditions remain basically unchanged, the Chinese working people allow their inherent impression to guide the design and build residential and settlements. For a long time, there were almost no changes in the form of residential buildings.

When migrating ethnic groups come to a brand-new land, the first thing they face is the question of "where to rely on". Only when most of the honest working people own houses will they have the courage to face production and life. The appearance of "home" in memory, the working scenes of building houses in the past, and the existing experience of craftsmen in the ethnic group will make them try to build houses that are exactly the same as before. However, due to migration to other places and changes in topography and natural resource conditions, people cannot obtain the original building materials. The old methods are not suitable for the new site, and people lack construction experience. They choose to use local materials and use new building materials to restore the experience, invisibly helping the region to make a choice for the building.

If this ethnic group develops a strong sense of superiority and identity due to the large number of people, strong clan 
concepts, and the ability of inter-ethnic communication to meet their needs, they will consciously distinguish between the houses they built and the houses of the aborigines to achieve the goal of maximizing one's own ethnic characteristics. However, as time changes, the building has its own rhythm of life. A settlement is repeatedly demolished and rebuilt, and normal metabolism begins. Immigrants and indigenous people have deepened exchanges. From the initial reservations to the exchange of existence, both parties are learning. The experience of the other party and the joint search for a more suitable construction method for the region, the form of residential and settlements eventually gradually settled and stabilized.

Relying on residential buildings and walking through the route of "Braving the Journey to Northeast", what you see is the sweat, blood and tears of the people being oppressed by the old rulers and driven by the harsh nature. After the baptism of time and difficulties, the flowers of architecture are born. It is never giving up the dream of pursuing a rich home. In the concession and conquest of nature by architecture, Chinese people have always written an architectural epic of neither complaining nor surrendering.

\section{References}

[1] Song Shuchun. Folk Houses in Northeast China[N]. Jilin Daily. 2017-11-9 (14).

[2] Yang Mingrong. (2015) Research on the regional characteristics of residential space in Jiaodong — Taking Mou's Manor in Yantai as an example. Master's thesis, Yantai University, Yantai.

[3] Li Sibo. (2019) Research on Traditional Residential Forms in the Coast of Western Liaoning from the Perspective of Communication. Master's Thesis, Dalian University of Technology, Dalian.

[4] Yang Gusheng. Lu Yuanding. Chinese Civil Housing Architecture. Guangzhou: South China University of Technology Press; 2003. 